\title{
La main qui prête serment
}

\section{Erhard Taverna}

Dr med., membre de la rédaction

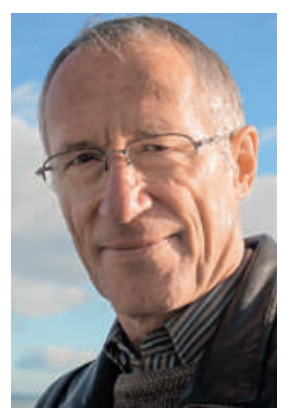

Le serment est un pacte avec le diable ou un pacte avec Dieu. Quiconque rompt sa promesse est voué à la damnation ou, dans les sphères terrestres, passible du code pénal. Faire serment, en levant ou non la main droite, c'est promettre une fidélité indéfectible à un chef, à un drapeau, ou s'engager devant un tribunal à dire toute la vérité et rien que la vérité. Dans notre Etat séculier, tout membre élu à l'Assemblée fédérale prête serment ou fait la promesse solennelle suivante: «Je jure devant Dieu tout-puissant (ou: je promets) d'observer la Constitution et les lois et de remplir en conscience les devoirs de ma charge.» Lélu qui refuse renonce à sa fonction, comme le précise l'article 3 de la loi de 2003 sur le Parlement. L'Association Médicale Mondiale se contente depuis 1948 d'engager les médecins à consacrer leur vie au service de l'humanité. Dans la Déclaration de Genève, dernièrement révisée en 2006, le médecin est appelé à «maintenir, dans toute la mesure de [ses] moyens, l'honneur et les nobles traditions de la profession médicale» dans l'intérêt du patient.

Dans le Bulletin des médecins suisses, un groupe de travail interdisciplinaire a proposé un énoncé actualisé du serment qui se prononce contre la tutelle des lois de l'économie, contre la déprofessionnalisation et contre la tendance croissante à se dérober aux responsabilités. Il semble que le corps médical ait le moral en berne car d'après cette commission, l'identité professionnelle et l'éthique sont soumises à de fortes pressions. La confiance du médecin en ses propres valeurs, dit-elle, doit être renforcée par des principes éthiques et des valeurs qui ne souffrent aucune équivoque. On parle aussi d'introduire une prestation de serment contraignante à chaque nouvelle prise de fonctions pour favoriser une conception commune de la profession. De brèves déclarations d'intention - dix-huit en tout donnent une première idée des exigences qu'il faudra observer. Le caractère lénifiant et peu incisif des articles proposés contraste avec le pathos avec lequel on avait appeléà repenser de fond en comble la portée de ce serment. Beaucoup de détails n'y ont pas leur place, notamment tout ce qui est plus ou moins rigoureusement défini et réglementé dans les nombreuses prises de position, recommandations et déclarations d'intention publiées par ailleurs.

Nous ne sommes plus des prêtres. Beaucoup de choses ont changé depuis les invocations d'Apollon, d'Asclépios, d'Hygée et autres divinités du Parthénon du temps d'Hippocrate. A quel dieu faut-il aujourd'hui faire allégeance? Et comment résumer la pluralité des opinions en une formule qui prétende être plus qu'un simple code des conve- nances? Dans le texte d'introduction, le grief par les auteurs d'une dévalorisation du statut est révélateur de leurs craintes plus profondes. La médecine s'est spécialisée et perfectionnée avec succès, en collaboration étroite avec d'autres groupes professionnels. Les associations de consommateurs et les groupes d'entraide, actifs et bien organisés, veulent avoir leur mot à dire dès lors que le bien des patients est en jeu. Dans les pays démocratiques, les citoyens - dont les médecins - sont souvent appelés à se prononcer sur des mesures qui régissent une grande partie des actes médicaux. A une confortable majorité, nos représentants assermentés au Parlement croient avoir trouvé dans la concurrence, telle que l'offre une économie de marché aussi déréglementée que possible, la panacée contre tous les défauts réels ou imaginaires du système. La médecine est priée d'assimiler ce mode de pensée axé sur le profit et de produire du rendement, une évolution dans laquelle le groupe de travail voit à juste titre une menace pour de nombreuses valeurs d'une importance centrale aux yeux de la plupart des médecins. Croire qu'un serment pourrait y changer quelque chose comme par magie confine cependant au mysticisme. Il serait souhaitable que cette préoccupation légitime suscite une discussion qui s'étende aux autres cercles concernés. Malheureusement, un serment ne peut rien contre la bêtise, l'arrogance, l'opportunisme et la cupidité dans nos propres rangs. Il ne suffit pas de se référer à nos prétendument si nobles traditions. L'honneur et la dignité d'une profession sont des valeurs fictionnelles qu'il tient à chacun de se construire. Les membres des professions médicales sont sollicités à double titre: en tant que citoyens, pour élire des politiciens compétents, et en tant que professionnels crédibles qui ont valeur d'exemple pour montrer à la relève ce qu'implique un travail consciencieux, responsable et à vocation sociale. Ou, pour faire plus simple: nous devons d'abord balayer devant notre propre porte et examiner d'un œil critique à quel point nos collègues ont repris à leur compte le principe du rendement. L'image dont ils jouissent semble encore intacte. Comment expliquer sinon que tant de jeunes gens se destinent à des études de médecine malgré la rigueur des conditions d'admission? Cette génération doit être la cible de tous les efforts visant une amélioration. Nous avons besoin de bons éducateurs et formateurs résolus à transmettre non seulement les aptitudes professionnelles du médecin, mais aussi la valeur ajoutée, indissociable de son statut. 